\title{
PEMBERDAYAAN MASYARAKAT PANGGUNGHARJO, SEWON, BANTUL DALAM MENINGKATKAN KEMAMPUAN LITERASI
}

\author{
Oleh: \\ Kelompok II.A. Sewon Bantul KKN Ramadhan 2017 \\ Universitas Ahmad Dahlan
}

\begin{abstract}
Abstrak
Permasalahan yang ada di masyarakat Panggungharjo yaitu kurangnya minat baca masyarakat, kurangnya pengetahuan masyarakat mengenai peran penting teknologi, kurangnya kemampuan keterampilan membaca puisi anak-anak, dan kurangnya kesadaran masyarakat tentang pentingnya pola asuh anak. Maka program KKN UAD difokuskan pada kemampuan literasi meliputi: pelatihan parenting, pelatihan Microsoft office, pendirian taman baca dan lomba festival anak soleh. Dampak dari kegiatan yang dilaksanakan yaitu: 1) masyarakat mengetahui tata cara pola asuh anak yang benar, 2) peningkatan kemampuan keterampilan anak menggunakan teknologi dalam hal ini yaitu mengoperasikan Microsoft office, 3) masyarakat gemar membaca setelah adanya fasilitas taman bacaan, 4) meningkanya kepercayaan diri masyarakat.
\end{abstract}

Kata kunci: pemberdayaan, panggungharjo, literasi.

\section{Abstract}

Problems that exist in Panggungharjo society are lack of reading interest, lack of public knowledge about the important role of technology, lack of reading skill ability of children, and lack of public awareness about the importance of parenting. So UAD's KKN program is focused on literacy skills including: parenting training, Microsoft office training, reading park establishment and soleh festival contest. The impact of the activities undertaken are: 1) the community knows the correct way of parenting, 2) the improvement of children's skill in using the technology in this case that is operating Microsoft office, 3) the community likes to read after the facility of reading garden, 4) meningkanya trust self society. Keywords: empowerment, panggungharjo, literasi.

\section{A. PENDAhUluan}

Panggungharjo adalah desa di kecamatan Sewon, Bantul, DIY, Indonesia. Gambaran umum Desa Panggungharjo yang berpenduduk 25.727 Jiwa dengan luas wilayah 564,54 Ha, berada di Kecamatan Sewon, secara administrasi dibatasi, sebelah Utara berbatasan dengan Kota Yogyakarta, Timur berbatasan Kelurahan Bangunharjo. Selatan berbatasan dengan Desa Timbulharjo dan Pendowoharjo, serta Barat berbatasan dengan Desa Tirtonirmolo Kecamatan Kasihan.

Terdapat dua jalan provinsi menuju pusat pemerintahan kabupaten Bantul, yaitu jalan Bantul yang melewati pedukuhan Dongkelan dan Kweni, dan jalan Parangtritis yang melewati pedukuhan Pandes, prancak Glondong dan Cabean. Secara topografi Desa Panggungharjo merupakan daerah dataran dengan ketinggian berkisar 45 meter diatas permukaan air laut. Berdasarkan karakteristik sumber daya alamnya Desa Panggungharjo terbagi dalam 3 bagian yaitu: Kawasan budi daya pertanian lahan basah yang meliputi pedukuhan Geneng, Garon, Cabean dan Ngireng-ireng. Kawasan pusat pemerintahan dan perekonomian yang meliputi pedukuhan Pandes, Glondong, Sawit, Jaranan, Kweni dan 
Pelemsewu. Kawasan aglomerasi perkotaan, yang meliputi pedukuhan Dongkelan, Glugo, Krapyak Kulon, Krapyak Wetan.

Berdasarkan kondisi geografis, wilayah desa Panggungharjo merupakan salah satu wilayah yang berdekatan dengan kota Yogyakarta. Untuk jalur utama lalu lintas antar daerah / antar provinsi terdapat ring road (jalan lingkar) selatan yang terletak di wilayah utara desa Panggungharjo, juga jalan Bantul dan jalan Parangtritis.

Beberapa permasalahan yang ditemukan di Panggungharjo yaitu: 1) kurangnya minat baca masyarakat, 2) kurangnya pengetahuan masyarakat mengenai peran penting teknologi, 3) kurangnya kemampuan keterampilan membaca puisi anak-anak, 4) kurangnya kesadaran masyarakat tentang pentingnya pola asuh anak.

Peran serta masyarakat dalam melaksanakan program-program sangat penting karena tanpa adanya peran serta masyarakat, program-program tidak akan terlaksana. Berdasarkan permasalahan tersebut, maka ditetapkan tujuan program KKN ini adalah memberdayakan masyarakat Panggungharjo yang berkaitan dengan literasi.

\section{B. METODE PELAKSANAAN}

Untuk mencapai tujuan yang diharapkan, program KKN di Panggungharjo dilakukan dengan pemberdayaan masyarakat melalui pendidikan masyarakat, difusi ilmu pengetahuan dan teknologi, dan praktek langsung. Ringkasan metode pelaksanaan beserta jam kerja efektif mahasiswa (JKEM) tersaji pada tabel I.

Tabel I. Metode, Kegiatan, JKEM dan keterlibatan mahasiswa

\begin{tabular}{|l|l|l|l|l|}
\hline No. & \multicolumn{1}{|c|}{ Metode } & \multicolumn{1}{|c|}{ Kegiatan } & \multicolumn{1}{|c|}{ JKEM } & \multicolumn{1}{|c|}{$\begin{array}{c}\text { Jumlah mahasiswa yang } \\
\text { terlibat }\end{array}$} \\
\hline 1. & $\begin{array}{l}\text { Pendidikan } \\
\text { masyarakat }\end{array}$ & $\begin{array}{l}\text { Pelatihan } \\
\text { parenting }\end{array}$ & $1 \times 2$ jam & 3 \\
\hline 2. & Disfusi iptek & $\begin{array}{l}\text { Pelatihan } \\
\text { Microsoft Word }\end{array}$ & $2 \times 2$ jam & 3 \\
\hline 3. & Praktik & Taman Bacaan & $3 \times 2$ jam & 9 \\
\hline & & $\begin{array}{l}\text { Festival Anak } \\
\text { Soleh }\end{array}$ & $1 \times 3$ jam & 26 \\
\hline
\end{tabular}

\section{HASIL, PEMBAHASAN, DAN DAMPAK}

\section{Profil Desa Panggungharjo}

Desa Panggungharjo berpenduduk sebanyak 27.444 jiwa dengan luas wilayah 564,54 Ha, berada di Kecamatan Sewon dibatasi, sebelah Utara berbatasan dengan Kota Yogyakarta, Timur berbatasan Desa Bangunharjo. Selatan berbatasan dengan Desa Timbulharjo dan Pendowoharjo, serta Barat berbatasan dengan Desa Tirtonirmolo Kecamatan Kasihan. Terdapat dua jalan propinsi menuju pusat pemerintahan kabupaten Bantul, yaitu Jalan Bantul yang melewati pedukuhan Dongkelan dan Kweni, dan Jalan Parangtritis yang melewati pedukuhan Pandes, prancak Glondong dan Cabean.

Desa Panggungharjo dibagi menjadi 14 (empat belas) Pedukuhan, antara lain : 
Diterbitkan oleh Lembaga Pengabdian kepada Masyarakat

Universitas Ahmad Dahlan Yogyakarta

1. Pedukuhan Garon

2. Pedukuhan Cabean

3. Pedukuhan Ngireng-ireng

4. Pedukuhan Geneng

5. Pedukuhan Jaranan

6. Pedukuhan Prancak Glondong

7. Pedukuhan Pandes

8. Pedukuhan Sawit

9. Pedukuhan Kweni

10.Pedukuhan Pelemsewu

11.Pedukuhan Glugo

12.Pedukuhan Dongkelan

13.Pedukuhan Krapyak Kulon

14.Pedukuhan Krapyak Wetan

Warga di Desa Panggungharjo sebagian besar merupakan masyarakat yang berpendidikan, walaupun jumlah warga yang mencapai pendidikan Perguruan Tinggi hanya sekitar 10\%, namun sudah lebih dari 50\% warga Desa Panggungharjo telah mengenyam pendidikan di berbagai tingkatan, hal tersebut merupakan modal untuk pembangunan yang sangat baik.

\section{Tingkat Pendidikan Desa Panggungharjo}

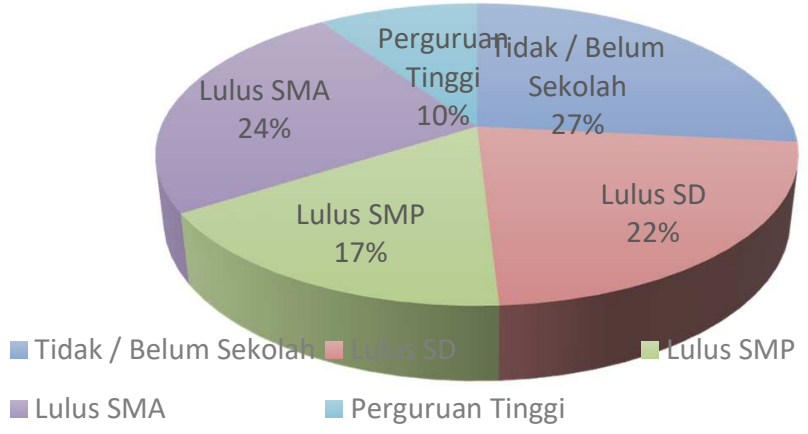

Jumlah penduduk produktif di wilayah Desa Panggungharjo mayoritas yakni usia 15-49 tahun dengan jumlah mencapai 15.102 jiwa. Mereka mampu bertahan di daerahnya dan tidak beraktifitas maupun mencari mata pencaharian keluar, hal ini karena sudah mulai berkembangnya beberapa pekerjaan sampingan maupun utama selain bertani, jika bekerja di kota pun mereka akan tetap pulang ke desanya dan lebih memilih melakukan perjalan pulang pergi setiap hari.

Dampak dari kegiatan tersebut adalah, semakin dekatnya emosional yang terjadi ditengah-tengah masyarakat, dapat dilihat dari kehidupan sehari-hari masyarakat semisal, gotong royong mingguan, pertemuan rutin RT, pertemuan ibu-ibu, dan ritual keagamaan yang dalam forum-forum tersebut bagi masyarakat merupakan suatu kewajiban sebagai bentuk solidaritas dalam persaudaraan. 
Penduduk produktif yang lebih banyak, akan menjadi penggerak dalam setiap proses pembangunan maupun proses lain yang ada, seperti bentuk kegiatan usaha baru di luar bidang pertanian yakni toko, koveksi, elektronik, rumah makan, dan sebagainya

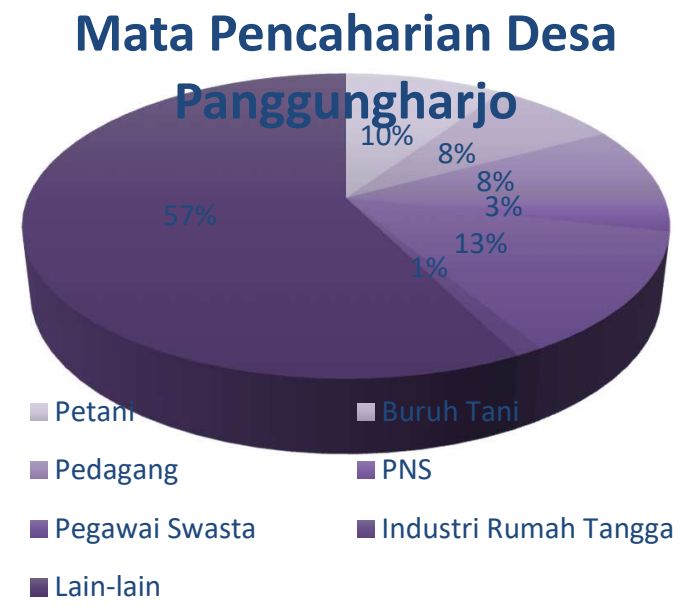

\begin{tabular}{|c|c|}
\hline $\begin{array}{l}\text { Laki- } \\
\text { laki }\end{array}$ & Perempuan \\
\hline 13,801 & 13,643 \\
\hline
\end{tabular}

\section{Jensi K€}

Pang६ 
Diterbitkan oleh Lembaga Pengabdian kepada Masyarakat

Universitas Ahmad Dahlan Yogyakarta

Gambaran.1 pelaksanaan

Gambar aktivitas mahasiswa KKN UAD dan masyarakat Panggungharjo yaitu sebagai berikut.

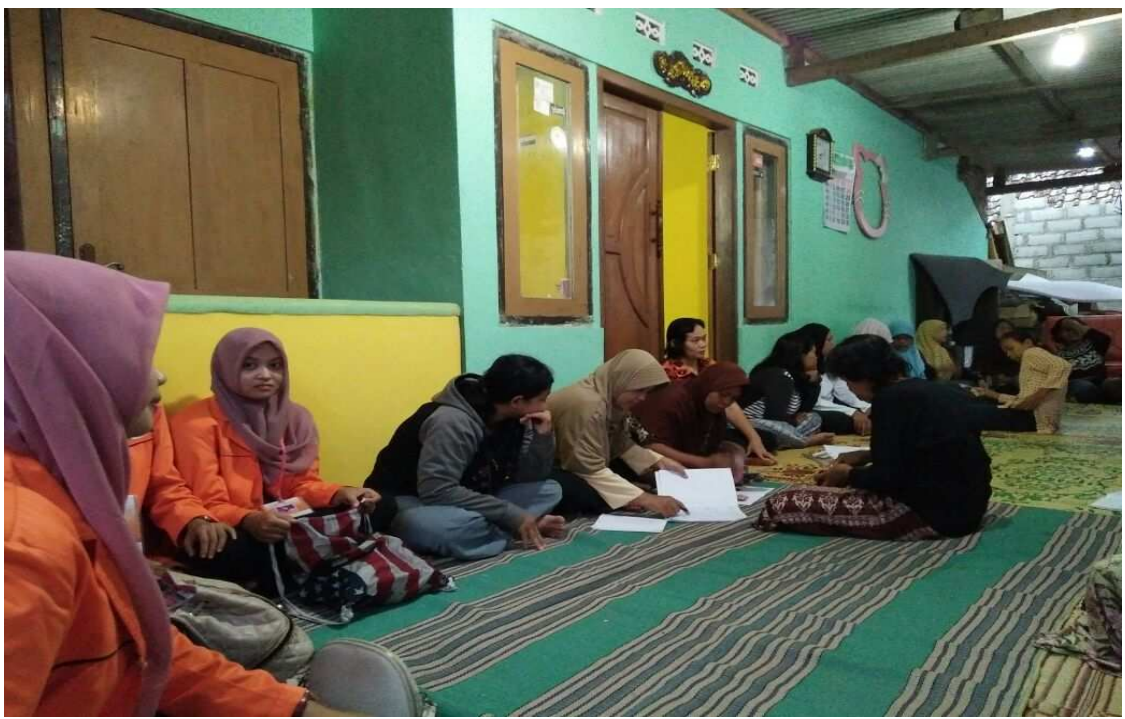

Progam ini ditujukan untuk ibu-ibu yang ada di RT.06 Kweni, yang dilaksanakan pada tanggal 20 Mei 2017. Program parenting merupakan program yang bersi tentang informasi pola asuh pada anak normal dan disabilitas yang dikemas menggunakan ilmu psikologi sehingga penyulihan tersebut lebih memfokuskan pada pola asuh dari mental anak. Program ini dilakukan dengan cara memberikan informasi melalui penyuluhan kepada ibu-ibu.

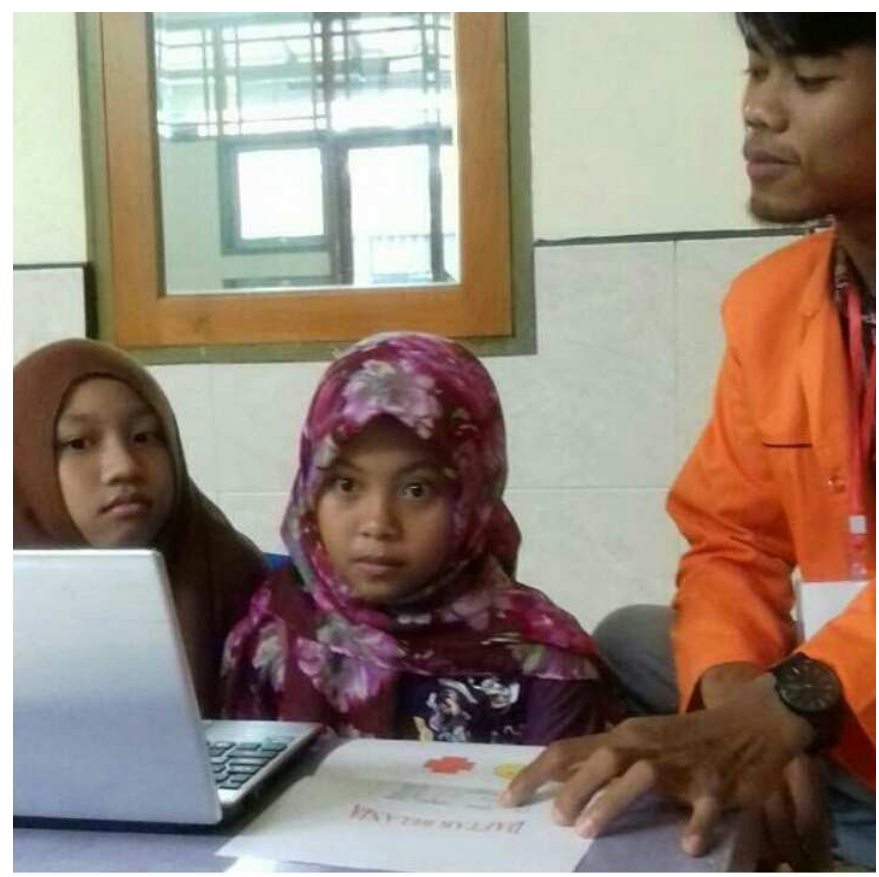


Program pelatihan Microsoft Office ditujukan untuk anak-anak di desa Panggungharjo. Dengan dilakukan program ini diharapkan anak-anak di desa Panggungharjo mulai mengenal teknologi sejak dini, minimal mengetik menggunakan Microsoft Word atau menginput data menggunakan Microsoft Exel. Pelatihan ini dilakukan secara berkelompok supaya anak-anak bisa saling membantu untuk praktik mengooperasikan Microsoft office, mulai dari membuka hingga menyimpan file.

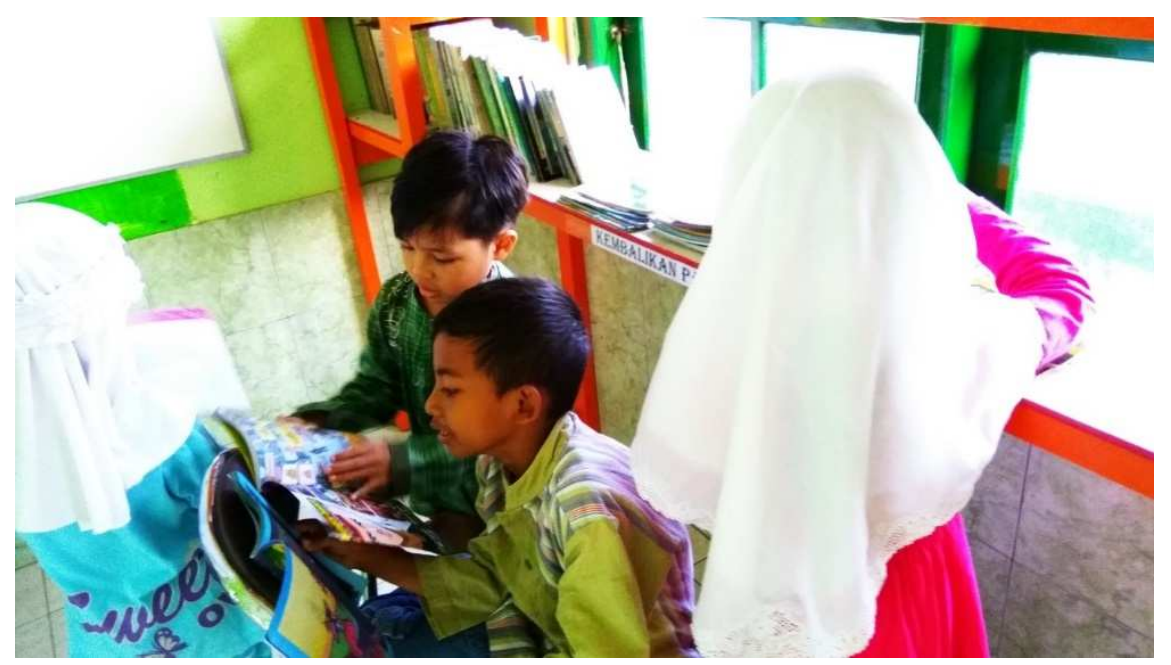

Taman Bacaan Masyarakat adalah sebuah tempat / wadah yang didirikan dan dikelola baik masyarakat maupun pemerintah untuk memberikan akses layanan bahan bacaan bagi masyarakat sekitar sebagai sarana pembelajaran seumur hidup dalam rangka peningkatan kualitas hidup masyarakat di sekitar Taman Baca. Taman bacaan sebagai medium pengembangan budaya baca merupakan tempat mengakses berbagai bahan bacaan: seperti buku pelajaran, buku keterampilan praktis, buku pengetahuan, buku keagamaan, buku hiburan, karya-karya sastra serta bahan bacaan lainnya yang sesuai dengan kondisi obyektif dan kebutuhan masyarakat sekitar dan minat baca yang baik. 


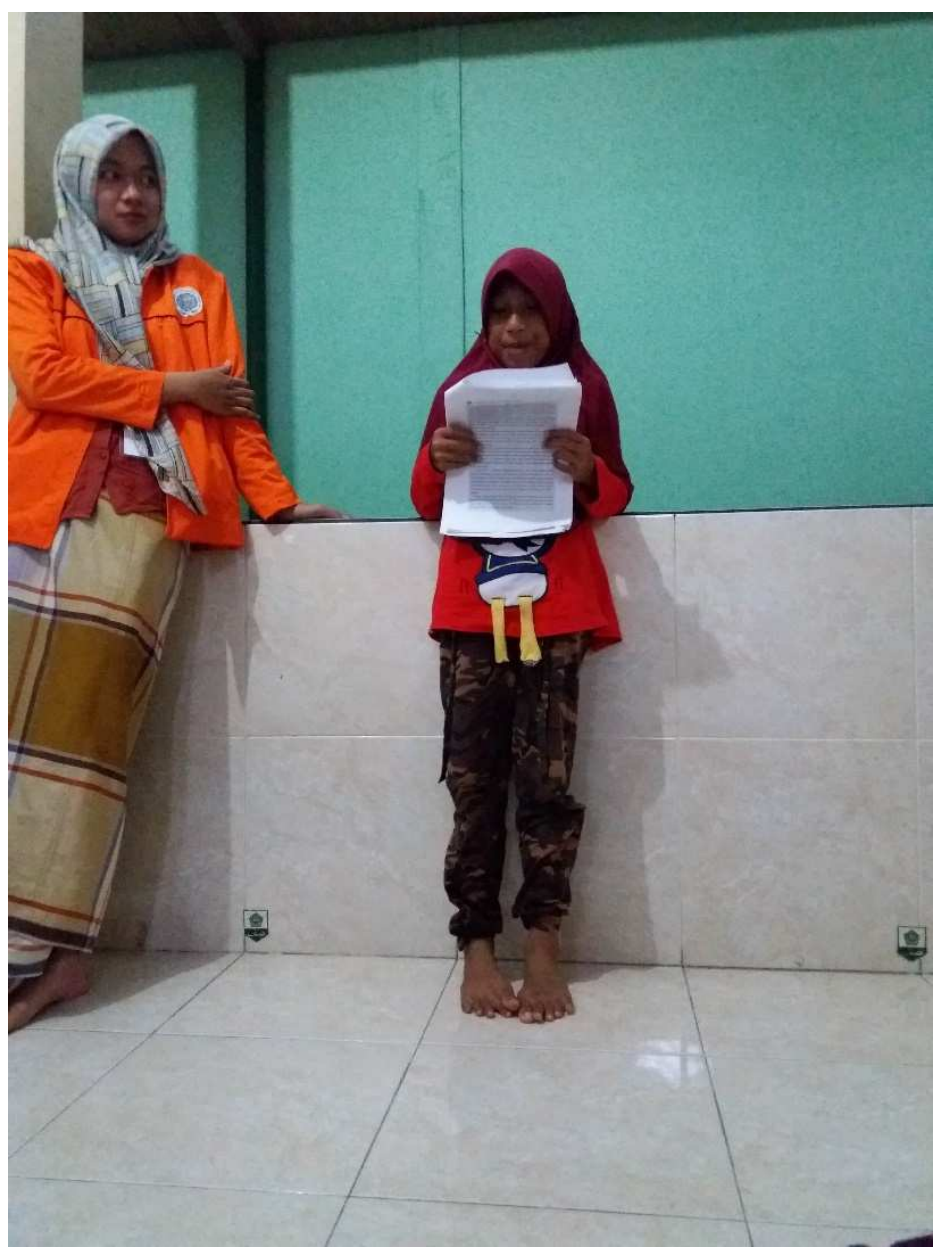

Membaca merupakan suatu kegiatan meresepsi, menganalisa, dan mengintepretasi yang dilakukan oleh pembaca untuk memperoleh pesan yang hendak disampaikan oleh penulis dalam media tulisan. Kemampuan membaca sangat penting bagi kehidupan kita. Oleh karena itu kita sebagai makhluk sosial tak bisa lepas dari ketrampilan membacaAdapun maksud dan tujuan dari kegiatan ini agar anak-anak dapat menyalurkan bakat mereka dalam menulis dan membaca puisi karangan mereka sendiri. Sasaran kegiatan ini ditujukan kepada anak-anak di Kecamatan Sewon.

\section{KESIMPULAN}

Program KKN UAD dalam memberdayakan masyarakat Panggungharjo untuk meningkatkan literasi telah berjalan dengan baik. 
